\title{
O PAPEL DAS REDES TEMÃTICAS NA FORMULAÇÃO DE AGENDAS: UM ESTUDO SOBRE A PRORROGAÇÃO DO PRONON
}

Patricia Del Claro

\section{// resumo}

O presente trabalho analisa de que forma atores da sociedade civil podem influenciar a agenda governamental, tendo como estudo de caso a prorrogação do Programa Nacional de Atenção Oncológica (PRONON). O PRONON, programa de incentivo fiscal na área da saúde, foi criado pela Lei no 12.715 de 17 de setembro de $2012 \mathrm{com}$ o objetivo de direcionar recursos para organizações da sociedade civil que atuam com oncologia. Inicialmente, seu prazo de vigência era até 2016. Porém, preocupados com o encerramento do programa, atores da sociedade civil se articularam para solicitar sua prorrogação até 2021. A proposta deste trabalho é descrever como se deu esse processo de agendamento a partir dos conceitos de agenda-setting (KINGDON, 2011) e redes temáticas (CAPELLA e BRASIL, 2015a; 2015b). A partir das ideias propostas por Kingdon (2011), concluímos que, neste estudo de caso, a agenda foi influenciada por atores da sociedade civil, mas competem aos atores governamentais as decisões sobre a agenda das políticas públicas.

palavras-chave: Redes Temáticas | PRONON | Políticas Públicas

Sociedade Civil 
OGIFE 


\section{artigos \\ GIFE}

\section{INTRODUÇÃO}

Uma das variáveis considerada nos estudos sobre formação de agenda - em específico, agenda governamental -, é a influência de atores não governamentais nesse processo. Muitas análises existentes sobre a interação entre governo e Organizações da Sociedade Civil (OSCs) procuram identificar os formatos ${ }^{1}$ das interações entre esses atores.

O presente trabalho traz uma breve descrição sobre os conceitos de agenda e sobre a capacidade dos atores não governamentais de influenciar as agendas governamentais com a apresentação de um estudo de caso sobre a prorrogação do Programa Nacional de Atenção Oncológica (PRONON).

Criado pela Lei $\mathrm{n}^{\circ} 12.715$ de 17 de setembro de 2012, o PRONON tem como finalidade destinar recursos via renúncia fiscal para instituições de saúde que atuam com oncologia. Pela lei, a vigência do programa seria até 2016 para doações de pessoas jurídicas (PJ) e 2017 para doações de pessoas físicas (PF) (BRASIL, 2013).

Em 2015, preocupados com o encerramento do programa em 2016/2017, membros da Rede Temática (RT) de Saúde, do Grupo de Institutos Fundações e Empresas (GIFE), e da Associação Brasileira de Instituições Filantrópicas de Combate ao Câncer (ABIFICC) iniciaram um processo de mobilização das organizações da sociedade civil e articulação com membros do Ministério da Saúde e do Legislativo com a finalidade de agendar a prorrogação da vigência do PRONON. Vale destacar que a mesma lei que instituiu o PRONON criou junto o Programa Nacional de Atenção da Saúde da Pessoa com Deficiência (PRONAS/PCD). Porém, o foco deste estudo é o PRONON, mesmo que ambos os programas sejam tema da RT de Saúde e tenham passado pelo processo de prorrogação do prazo de vigência.

Este trabalho parte da análise e texto apresentado pela autora no $9^{\circ}$ Congresso da Associação Latino Americana de Ciência Política (ALACIP) (CLARO, 2017) sobre o processo de prorrogação do PRONON.

\footnotetext{
1 CLARO, Patricia D. Possibilidades e constrangimentos na gestão participativa: um estudo de caso do Programa Cultura Viva. 2013. Dissertação (Mestrado em Ciência Política) - Curso de Pós-graduação em Ciência Política, Universidade Federal do Paraná, Curitiba, 2013.

NOGUEIRA, Marco Aurélio. Sociedade Civil, entre o político-estatal e o universo gerencial. Revista Brasileira de Ciências Sociais, v. 1, n. 52, jun. 2003.

TEIXEIRA, Ana Claudia Chaves. Identidades em Construção: as organizações não-governamentais no processo brasileiro de democratização. 2000. Dissertação (Mestrado em Ciência Política), Universidade Estadual de Campinas, São Paulo, 2000.
} 


\title{
O CONCEITO DE AGENDA-SETTING NA FORMULAÇÃO DE POLİTICAS PÚBLICAS
}

\author{
Segundo a professora Celina Souza (2018):
}

\begin{abstract}
"Desde quando os governos passaram a assumir maiores responsabilidades na formulação e na implementação de políticas públicas, a coordenação de políticas, em suas diversas modalidades, entrou na agenda de temas que buscavam respostas para seu melhor entendimento e aperfeiçoamento” (SOUZA, 2018, p. 7).
\end{abstract}

Em seu trabalho Estado da Arte da Pesquisa em Politicas Públicas (2007), Souza destaca a existência de duas correntes: a europeia, com estudos teóricos sobre o papel do Estado, e a norte-americana, com foco mais propriamente na ação dos governos (SOUZA, 2007). Segundo a autora, um dos objetos de estudo da corrente norte-americana é a formação de agenda (agenda-setting) no sentido de compreender porque determinados assuntos são levados em consideração pelos governos e outros não e o papel dos atores para vetar ou incentivar a agenda governamental (SOUZA, 2006).

Vale destacar que existem distintos conceitos de agenda (agenda-setting). McCombs (2009), estudioso da área de comunicação, foi quem primeiro definiu agenda como a capacidade dos meios de comunicação de massa de influenciar a opinião pública.

Kingdon (2011) é outro importante autor do campo das políticas públicas que distingue diferentes conceitos de agenda. Em seu livro Agendas, Alternatives and Public Policies, Kingdon analisa o processo de agenda-setting: "Sabíamos como os assuntos eram decididos, mas pouco sobre como tornavam-se assuntos importantes" (KINGDON, 2011, p. 17, tradução livre). A questão do autor era analisar como certos temas eram identificados e transformados em problemas e por que outros assuntos nunca eram agendados. Em seu trabalho, o autor distingue os conceitos de agenda do governo (governmental agenda), agenda de decisões (decision agenda) e alternativas (alternatives). Como ele mesmo destaca, o termo 'agenda' é utilizado de distintas formas: ora para se referir a um evento do governo, ora para tratar de propostas e temas. $\mathrm{O}$ autor define agenda como: "uma lista de assuntos ou problemas aos quais profissionais estão prestando séria atenção em determinado tempo” (KINGDON, 2011, p.3, tradução livre).

Para Capella e Brasil (2015b), os estudos sobre agenda-setting surgiram com o "desdobramento de análises voltadas à investigação de processos de participação política e seus limites no contexto da teoria democrática (...)" (idem, p. 5). Os dois autores descrevem no trabalho A trajetória dos estudos sobre a agenda de políticas públicas (2015b) um traçado histórico sobre os estudos de agenda política e suas diferentes interpretações de acordo com diferentes áreas do conhecimento (CAPELLA e BRASIL, 2015b).

Capella e Brasil (2015b) também analisam como as teorias e focos das pesquisas sobre agenda-setting foram mudando com o tempo. Nas décadas de 1960 e 1970, com o surgimento dos meios de comunicação de massa, os principais estudos eram sobre o processo de definição das notícias e seus efeitos na agenda pública e na definição de políticas públicas (CAPELLA e BRASIL, 2015). Para os autores, é na década de 1970 que começam os estudos da agenda pela Ciência Política, tendo como principais autores Cobb e Elder (1971), que foram os primeiros a utilizar o termo policy agenda-setting (COBB e ELDER, 1971).

Cobb e Elder (1971) problematizam a participação do cidadão comum na política, sobre sua racionalidade e responsabilidade. Os autores discorrem sobre a pouca participação e interesse do cidadão comum na vida pública, ao contrário do que consideravam alguns teóricos da época. Além disso, as pessoas que participavam, o faziam com base em pouco ou nenhum conhecimento (COBB e ELDER, 1971).

A questão apresentada pelos autores é a seguinte: dadas as restrições do sistema político, como determinados grupos poderiam agendar suas demandas? Para tentar responder, analisam o processo de formulação da agenda política com o objetivo de entender como determinados assuntos são agendados e quem são os atores que participam desse processo. Os autores destacam a importância dos políticos profissionais 
na formulação da agenda e a capacidade de barganha com outros tomadores de decisões. Alguns fatores seriam decisivos para que grupos fora do aparato institucional conseguissem influenciar a agenda política, como os recursos e a posição econômica (COBB e ELDER, 1971).

Um exemplo que os autores citam são os estudantes que participaram do movimento anti-guerra nos Estados Unidos. Esses grupos só conseguiram chamar atenção para sua pauta depois que grupos mais influentes se juntaram ao movimento (COBB e ELDER, 1971).

Kingdon (2011) também destaca o papel dos atores fora do aparato estatal na formação das agendas. Neste caso, esses atores teriam o papel de transferir suas demandas para a agenda do governo por meio de mobilizações e de lideranças relevantes no cenário político, entre outros (KINGDON, 2011).

\section{O PAPEL DAS REDES TEMÄTICAS NA FORMAÇÃO DAS AGENDAS GOVERNAMENTAIS}

Considerando o papel dos atores fora do aparato estatal na formulação das agendas, a questão é entender em que medida esses grupos conseguem gerar mudanças ou agendar temas, uma vez que as decisões necessitam dos policy makers.

No que diz respeito ao perfil dos participantes, Kingdon cita os seguintes grupos: 1) os grupos de interesses; 2) acadêmicos, pesquisadores e consultores; 3) a mídia; 4) grupos políticos que não estão no governo, como, por exemplo, partidos; 5) a opinião pública (KINGDON, 2011).

Dos acima citados, os grupos de interesses aparecem como o mais importante para Kingdon. O autor realizou pesquisas sobre as políticas de saúde e transporte nos Estados Unidos e verificou que grupos de interesses com mais influência sobre a política de transporte eram as empresas e indústrias. Dos 12 casos sobre políticas de transporte, nove sofriam influência de grupos empresariais; já nas políticas de saúde, dos 11 casos estudados, somente dois tiveram influência desse segmento (KINGDON, 2011).

Outra modalidade apresentada por Kingdon (2011) seriam os grupos de consumidores ou ambientalistas, que atuariam no interesse público. Segundo entrevistados na pesquisa feita pelo autor, o desinteresse pela atuação em partidos políticos teria diminuído devido ao surgimento desses grupos de interesses públicos.

A ação desses grupos acima descritos poderia se dar de distintas formas. Alguns grupos influenciariam as agendas e outros as alternativas consideradas pelos policy makers (KINGDON, 2011). Para o autor, os grupos mais articulados e com mais ações junto aos gestores públicos e políticos, teriam mais chances de ter suas demandas consideradas. Alguns exemplos citados por Kingdon (2011) são: a pressão exercida por trabalhadores para ter seguro saúde ou as questões das companhias de ônibus sobre os ônibus intermunicipais e terminais intermodais que combinassem trem e ônibus. Porém, mesmo com esses exemplos, para o autor é difícil assegurar que a formação da agenda se deu somente pela ação desses atores. Isso porque, para ele, um tema se torna agenda por uma complexidade maior de fatores e não somente por pressão de grupos.

Outro ponto importante para Kingdon (2011) são os recursos dos atores que aumentam as chances dos grupos de afetarem a agenda e as alternativas no sentido de propiciar vantagens ou desvantagens. Ter alto recurso político nem sempre é garantia de agenda por determinado grupo (KINGDON, 2011). Para o autor, os recursos importantes são: 1) o capital eleitoral, ou seja, a capacidade dos grupos de mobilizar e afetar os resultados das eleições; e 2) coesão no que diz respeito à "capacidade de convencer os oficiais do governo de que eles falam em uma só voz e verdadeiramente representam as preferências do grupo" (KINGDON, 2011, p. 52, tradução livre). Para ele, os interesses organizados têm mais atenção do que interesses que não estão organizados. Porém, mesmo esses recursos políticos e organizacionais não garantem que as questões dos grupos sejam agendadas. 
Capella e Brasil (2015a), em seu trabalho Análise de Políticas Públicas: uma revisão da literatura sobre o papel dos subsistemas, comunidades e redes (2015a), apresentam os principais teóricos e conceitos sobre esses grupos de atores fora do aparato estatal e sua capacidade de influenciar decisões governamentais.

Eles apresentam o conceito de Redes proposto por Heclo, um dos primeiros estudiosos a tratar das redes temáticas (issue networks), que seriam formadas por diversificados atores com um interesse comum, mas que atuariam de forma mais fluida (HECLO, 1978 apud CAPELLA e BRASIL, 2015a). Rhodes, também citado por Capella e Brasil (2015a), acredita que olhar para esses atores foi o que "permitiu o desenvolvimento de explicações sobre o relacionamento entre o Estado e os diferentes grupos que buscam influenciar a produção de políticas públicas, por um lado, e o interesse do próprio Estado em obter apoio desses grupos" (RHODES, 1988 apud CAPELLA e BRASIL, 2015a, p. 62). Para Rhodes, as principais características das redes temáticas seriam: 1) muitos participantes; 2) fluidez nas interações; 3) presença mais de conflitos que consensos; 4) interação baseada em consultas; 5) desigualdade na distribuição de poder (RHODES, 1988, apud CAPELLA e BRASIL, 2015a).

\section{REDES TEMÁTICAS E AGENDA DA SAÚDE: A PRORROGAÇÃO DO PROGRAMA NACIONAL DE ATENÇÃO ONCOLÓGICA (PRONON)}

Nascido como grupo informal em 1989 e institucionalizado em 1995, o Grupo de Institutos Fundações e Empresas (GIFE) é uma organização que congrega empresas, fundações e institutos que aportam recursos privados em projetos de finalidade pública de forma planejada, monitorada e sistemática. Possui, atualmente, mais de 150 associados que investem cerca de R\$ 3 bilhões de reais por ano, segundo dados disponíveis no site do GIFE.

Do total de associados ao GIFE, $86 \%$ afirmam alinhar seus projetos com políticas públicas e $45 \%$ possuem parcerias com o poder público (GIFE, 2017). Para os associados que não adotam esse tipo de atuação, os motivos são: dificuldades de realizar parcerias por conta do formato de funcionamento do poder público, receio de impactos negativos de imagem, descontinuidade por conta de mudanças políticas e excesso de burocracia (GIFE, 2017).

Na área específica de saúde, segundo dados do Censo GIFE 2016 (GIFE, 2017), 37\% dos associados investem nessa causa. Dos que atuam na saúde como área prioritária (13\%), o foco de atuação é na articulação com políticas públicas e na formação de profissionais.

De acordo com Andrade (2017), "um dos mais consistentes movimentos observados nas recentes edições do Censo GIFE tem sido as convergências do investimento social privado (ISP) com políticas públicas" (p. 50). Em sua análise, a partir dos dados do Censo GIFE 2016, um dos motivadores seria a vontade de atuação nas estruturas dos problemas sociais. Uma dessas formas de atuação seria por meio de advocacy. Do total de associados ao GIFE respondentes do Censo GIFE 2016 e que afirmaram atuar alinhados com políticas públicas, 23\% realizam ações de advocacy (GIFE, 2017).

Andrade (2017) aponta uma série de desafios para a atuação conjunta do setor privado com o público com vistas à implementação de políticas públicas. Uma delas é a própria dinâmica do setor público, que envolve não apenas o executivo, como o legislativo e judiciário. O autor sugere modelos de governança que propiciem a participação de atores da sociedade civil para a resolução de problemas sociais de uma forma eficiente. Diante desse cenário, o autor coloca a seguinte questão: "que estratégias para essas convergências podem funcionar melhor e gerar maior impacto ou, ainda, onde estão as melhores oportunidades para provocar mudanças?” (ANDRADE, 2017, p. 54). 
No presente trabalho, apresentamos a articulação de redes temáticas como uma possibilidade de influenciar políticas públicas, tendo como exemplo a Rede Temática de Saúde, criada pelo GIFE, e seu papel na prorrogação do Programa Nacional de Apoio à Atenção Oncológica (PRONON).

O GIFE, dentre as suas várias ações, iniciou um processo de articulação de redes temáticas para a discussão e possibilidade de ação conjunta entre associados em determinados temas ou áreas. Cabe ressaltar que essas redes atuam em temas específicos.

Em 2014, foi criada a Rede Temática de Saúde com a finalidade de debater o investimento social privado na área, com participação de associados ao GIFE de todo o Brasil interessados no tema. Segundo Fábio Deboni (2018), coordenador da Rede de 2014 a 2016, a ideia da RT de Saúde surgiu após o Congresso GIFE em 2014 e foi mobilizada inicialmente por dois associados: Instituto Sabin e Fundação Vale. De acordo com ele, nos dois anos em que foi coordenador, participaram dos encontros da Rede cerca de 70 pessoas, entre representantes dos associados ao GIFE e convidados.

Em notícia publicada pelo GIFE em março de 2015, Deboni destaca a importância da criação da Rede para estimular o investimento na área da saúde, tendo em vista que não havia muitos associados ao GIFE investindo nessa área (GIFE, 2015).

Lívia Zandonadi, que na época da criação da RT de Saúde era gerente de investimento social na área da saúde da Fundação Vale, em entrevista comentou que o que a motivou a participar da articulação da Rede Temática de Saúde foi a necessidade de conhecer experiências bem-sucedidas de projetos nessa área. Após o encontro no Congresso GIFE, Deboni e Zandonadi, junto com a equipe de gestores do GIFE, começaram a mobilização para iniciar as atividades da RT de Saúde.

A primeira reunião da RT de Saúde aconteceu no dia 14 de junho de 2014 e teve como objetivo convidar e mobilizar associados para participação na RT. Um mês depois, em 14 de julho de 2014, o tema do encontro foi sobre possibilidades de atuação do investimento social privado na área da saúde, com apresentação de casos (GIFE, 2016a). Paralelamente ao início da mobilização da RT de Saúde, o Programa Nacional de Apoio à Atenção Oncológica (PRONON) começava a aprovar e a executar os primeiros projetos com OSCs.

Criado em 2012 pelo governo da então presidente Dilma Rousseff, o PRONON tem como objetivo apoiar projetos de OSCs que atuam com oncologia por meio de incentivo fiscal para empresas doadoras e contribuintes. A Lei definiu a duração do PRONON de 2013 a 2016 para doações de empresas e a 2017 para doações de pessoas físicas. Ou seja, o programa tinha previsão de encerramento.

Segundo Zandonadi (2019), como era um programa recente e poucas instituições associadas ao GIFE o conheciam, os coordenadores da RT resolveram aproveitar a oportunidade e promoveram atividades para esclarecimento sobre o PRONON. Por se tratar de uma oportunidade de investimento social via renúncia fiscal, o debate sobre o PRONON gerou interesse por parte dos membros da RT de Saúde, segundo Deboni (2018).

Foram realizados os seguintes encontros: 17 de setembro de 2017, sobre o PRONON e PRONAS; 15 de abril de 2015, "Diálogo com Ministério da Saúde sobre PRONON e PRONAS"; 16 de setembro de 2015, “Oficina para investidores - PRONON e PRONAS" (GIFE, 2016a). Zandonadi (2019) comenta que esses encontros aumentaram o interesse dos participantes em investir em projetos aprovados pelo PRONON.

Como funciona o PRONON? As OSCs que atuam em assistência, pesquisa e formação na área oncológica se credenciam na coordenação do PRONON, no Ministério da Saúde, e apresentam projetos que são avaliados por uma equipe técnica. Após aprovação, as empresas interessadas e pessoas físicas podem doar até $1 \%$ do seu Imposto de Renda (IR) através da declaração completa. 
São várias as vantagens do PRONON. Primeiro, o programa incrementa o orçamento da pasta da saúde via renúncia fiscal. Segundo, ele possibilita que hospitais filantrópicos invistam em inovação e tecnologia na área oncológica, especialidade de alto custo e com constante desenvolvimento científico de novos tratamentos e equipamentos. Terceiro, abre espaço para a participação de empresas e cidadãos na execução de políticas públicas de saúde (CLARO, 2017).

Em seu primeiro ano (2013), o PRONON aprovou 23 projetos, totalizando R\$ 78.638.069,14. Em 2014, esse número aumentou para 60 projetos aprovados, no valor total de R\$211.101.004,75. De 2013 a 2016, o PRONON aprovou 169 projetos num valor total de R\$ 430.552.537,71 (CGU, 2016).

Um dos pontos levantados pelos participantes para a ação da Rede foi a necessidade de aproximação institucional entre o GIFE e o Ministério da Saúde para compreender e potencializar as possibilidades do PRONON. Em seguida, essa aproximação tornou-se necessária pela preocupação com o encerramento do programa em 2016/2017.

Foi feita uma série de encontros além da agenda com os participantes da RT de Saúde para discutir o PRONON: em 8 de maio de 2015, a RT realizou um encontro com a Associação Brasileira de Instituições Filantrópicas de Combate ao Câncer (ABIFICC), outro ator da sociedade civil que teve papel importante na prorrogação do PRONON; em 12 de maio de 2015, realizou audiência pública no Congresso Nacional sobre a agenda PRONON e PRONAS; e em 7 de agosto, realizou audiência com o Ministério da Saúde também para discutir os programas (GIFE, 2016a).

A RT de Saúde, que acabou tendo como uma de suas pautas prioritárias o PRONON, encaminhou junto aos dirigentes do GIFE a necessidade de posicionamento perante o pedido de prorrogação do PRONON e PRONAS. Foi elaborada, então, Carta de Posicionamento, conforme texto a seguir:

O GIFE - Grupo de Institutos Fundações e Empresas, por meio de sua Rede Temática de Saúde, torna público seu posicionamento favorável à prorrogação da vigência do Programa Nacional de Apoio à Atenção Oncológica (PRONON) e Programa Nacional de Apoio à Atenção à Saúde da Pessoa com Deficiência (PRONAS). Em seus primeiros anos de existência, PRONON e PRONAS demonstraram grande capacidade de mobilização de organizações sociais e investidores sociais privados motivados pela superação de importantes gargalos da saúde pública brasileira. Em pouco mais de 2 anos, mais de 400 organizações das cinco regiões do país se credenciaram junto ao Ministério da Saúde para apresentação de projetos. Os projetos apresentados e aprovados para captação tiveram o apoio de mais de 1.000 empresas que investiram aproximadamente R\$ 340 milhões. Estes investimentos têm garantido a realização de pesquisas de ponta, formação de recursos humanos e a ampliação da assistência nessas áreas graças ao trabalho intersetorial que envolve o Governo Federal, Organizações do Terceiro Setor e a Iniciativa Privada. A demanda, em 2015, de valores que superam R\$ 800 milhões em projetos demonstra que ainda existem muitos desafios a serem superados para garantia de serviços adequados de atenção à saúde de pacientes oncológicos e pessoas com deficiência. Para que esse modelo de trabalho não seja interrompido é de fundamental importância a prorrogação dos referidos programas. Previstos inicialmente para vigorarem até 31 de dezembro de 2016 pela Lei 12.715/2012, a prorrogação da validade dos programas possibilitará o aperfeiçoamento desses importantes mecanismos de financiamento para que possam alcançar mais resultados com maior agilidade. O GIFE reitera a valorização dos investimentos sociais em saúde e nosso interesse em contribuirmos com as políticas públicas neste setor. (GIFE, 2016c).

Segundo Deboni (2018) e Zandonadi (2019), não houve conflito por parte dos membros da RT de Saúde sobre esse posicionamento, o que mostra uma coesão do grupo em relação a essa agenda. Os entrevistados não souberam dizer se por parte do GIFE havia outro tipo de mobilização ou estratégia e se essa carta foi entregue aos membros do executivo e legislativo.

Além do importante papel da RT de Saúde na articulação e debate sobre a prorrogação do PRONON, outros protagonistas atuaram nesse processo, como é o caso da ABIFICC. Em 18 de maio de 2015, membros da ABIFICC se reuniram com membros do legislativo e executivo para discutir sobre a agenda do programa. 
Participaram da reunião o assessor da senadora Gleisi Hoffmann, Wagner Friaça, e Carlos Eduardo Sousa, coordenador do PRONON no Ministério da Saúde (ABIFICC, 2015a).

De acordo com notícia publicada no site da ABIFICC em 21 de agosto de 2015, em encontro com membros da Associação, a senadora Gleisi Hoffmann apresentou relatório sobre a Medida Provisória 675/2015 com emenda de sua autoria para a prorrogação do PRONON até 2021. Essa MP alteraria o Art. 4 da Lei 12.715/2012, que instituiu o programa. (ABIFICC, 2015b).

\section{Foto 1: Senadora Gleisi Hoffmann com membros da Abificc}

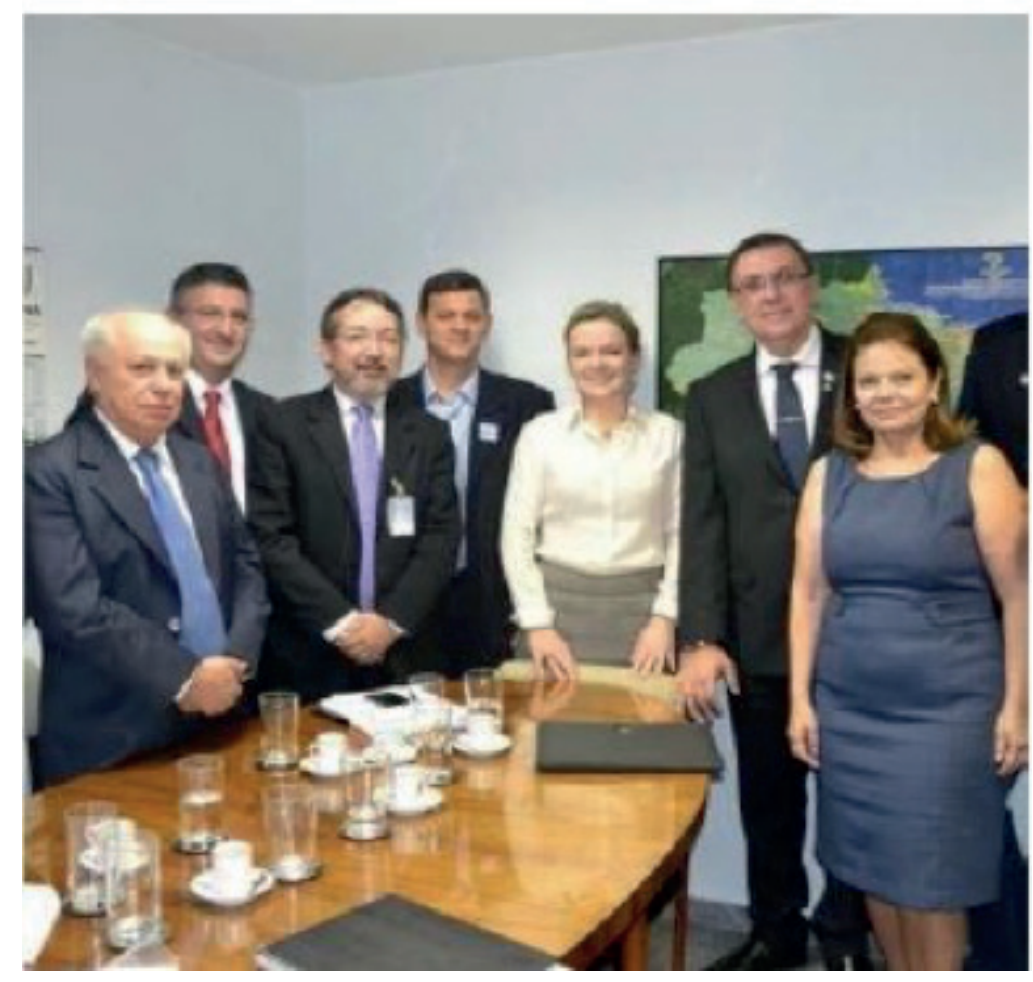

Fonte e crédito da foto: ABIFICC, 2015b

Em 15 de setembro de 2015, a prorrogação do PRONON foi aprovada no Senado Federal, conforme notícia no site do Instituto Oncoguia:

Nesta quarta-feira (15), o Senado Federal aprovou o Projeto de Lei que prorroga o prazo de validade dos programas PRONON e PRONAS-PCD de2016 para 2021. Com parecer positivo, o Projeto de Lei de Conversão $n^{\circ} 11$, de 2015, segue agora para a sanção da presidente Dilma Rousseff. De relatoria da Senadora Gleisi Hoffmann, o PL pretende prorrogar estes dois programas para além de 2016, ano em que os dois serão possivelmente encerrados, como define a Lei. Tanto o PRONON quanto o PRONAS foram implantados em 2013 pelo Ministério da Saúde para que pessoas físicas e jurídicas pudessem doar $1 \%$ do valor do imposto de renda para entidades, associações e fundações privadas sem fins lucrativos (INSTITUTO ONCOGUIA, 2015). 


\section{CONCLUSÕES}

Apesar da formação da agenda governamental depender dos policy makers, os atores fora do aparato estatal podem sim influenciar as agendas. Para isso, como foi tratado no presente trabalho, os recursos e a coesão do grupo em relação a um tema são fundamentais (KINGDON, 2011).

No caso específico sobre a agenda da prorrogação do PRONON, a Rede Temática de Saúde do GIFE teve um papel importante. Primeiro, em difundir entre seus participantes e associados o próprio programa como uma oportunidade de investimento na área da saúde por meio da renúncia fiscal. De acordo com dados do Benchmarking do Investimento Social Corporativo (BISC), os programas de incentivo fiscal na área da saúde incrementaram as doações nesse setor: "antes da sua existência, o BISC observou que as empresas investiam R\$ 31 milhões no campo. Após as novas leis, o investimento saltou para R\$ 114 milhões, sendo que $65 \%$ vem do incentivo fiscal”. (GIFE, 2016b, n.p.)

Segundo, a RT de Saúde acabou por realizar vários encontros sobre o PRONON mobilizando os membros para a importância desse tema e criando uma coesão no grupo em relação a esse assunto (KINGDON, 2011). Também aproximou os atores não governamentais ao gestor do programa: o Ministério da Saúde. Zandonadi (2019) comenta que a primeira reunião de membros da RT com o Ministério da Saúde foi para discutir como a RT poderia contribuir com o melhor desempenho do programa.

A partir dessas mobilizações da RT em torno do PRONON, que em 2015 começava a apresentar seus primeiros resultados, a importância da prorrogação do programa surgiu com a preocupação de seu encerramento. Ou seja, o PRONON tornou-se uma agenda prioritária para a RT de Saúde, que realizou, em 2015, reuniões com membros do executivo e legislativo (GIFE, 2016a). Vale destacar que outras instituições tiveram um papel fundamental nesse processo, como é o caso da ABIFICC.

Outro ponto que não podemos deixar de apontar é a atuação dos atores governamentais. Como a prorrogação do PRONON dependia de uma decisão do Congresso, havia a necessidade de interlocução com parlamentares e nesse caso quem levou a agenda para plenária foi a senadora Gleisi Hoffmann. Ressaltamos que o presente estudo não investigou se no processo de articulação dos atores da sociedade civil com os atores governamentais houve conflitos ou articulações com outros parlamentares, bem como qual era a receptividade dessa agenda junto à parlamentar contatada. $\mathrm{O}$ ponto central foi analisar a capacidade da sociedade civil de gerar agenda e a importância dos atores governamentais na tomada de decisão. O que percebemos pela prorrogação do programa é que a agenda não encontrou restrições ou resistência na sua aprovação.

O que podemos concluir a partir do que foi apresentado é que o caso analisado reforça a ideia da capacidade de atores da sociedade civil de influenciar e propor agendas desde que haja convergência sobre o tema agendado. Confirma também a necessidade de interlocução com atores governamentais, já que são esses atores que têm o poder de decisão nas instituições políticas.

Nesse sentido, o presente estudo apresentou como a mobilização de Redes Temáticas por parte do GIFE pode ser uma estratégia para que seus associados ampliem a participação na agenda de políticas públicas. E que essas redes devem se aproximar dos atores governamentais, uma vez que eles é que decidem as agendas dos governos. 


\section{REFERÊNCIAS BIBLIOGRÁFICAS}

ANDRADE, Sérgio. A difícil arte da mudança: construindo estratégias para gerar transformações sociais em parceria com o setor público. In: SAEZ, Erika Sanchez; SANTIAGO, Graziela; ZACCHI, José Marcelo (Orgs.). Censo GIFE 2016. 1. ed. São Paulo: GIFE, 2017. 256 p. Disponível em: < https://sinapse.gife.org.br/download/censo-gife-2016>. Acesso em: nov. 2018.

ASSOCIAÇÃO BRASILEIRA DE INSTITUIÇÕES FILANTRÓPICAS DE COMBATE AO CÂNCER (ABIFICC). Abificc se reúne com representantes do Legislativo e do Executivo para discussão sobre Pronon. São Paulo: ABIFICC, 2015a. Disponível em: 〈www.abificc.org.br〉. Acesso em: nov. 2018.

Senadora Gleisi: Apoio às Instituições Filantrópicas. São Paulo: ABIFICC, 2015b. Disponível em: < https://abificc.org. br/noticia/senadora-gleisi-apoio-as-instituicoes-filantropicas/>. Acesso em: nov. 2018.

BRASIL. Decreto n ${ }^{\circ}$ 7.988, de 17 de abril de 2013. Regulamenta os arts. $1^{\circ}$ a 13 da Lei ${ }^{\circ} 12.715$, de 17 de setembro de 2012, que dispõem sobre o Programa Nacional de Apoio à Atenção Oncológica (PRONON) e o Programa Nacional de Apoio à Atenção da Saúde da Pessoa com Deficiência (PRONAS/PCD). Disponível em: <http://www.planalto.gov.br/ccivil_03/_Ato20112014/2013/Decreto/D7988.htm>. Acesso em: 10 fev. 2019.

CAPELLA, Ana Claudia N.; BRASIL, Felipe Gonçalves. Análise de Políticas Públicas: uma revisão da literatura sobre o papel dos subsistemas, comunidades e rede. São Paulo: Novos estudos, 2015a. <Disponível em: < http://www.scielo.br/scielo.php?script=sci_arttext\&pid=S0101-33002015000100057>. Acesso em: nov. 2018.

A trajetória dos estudos sobre a agenda de políticas públicas. Teoria e Pesquisa. Revista de Ciência Política. Vol. 24 n.2, p. 4-17, 2015b.

CLARO, Patricia D. Agenda da saúde: um estudo sobre a prorrogação do Programa Nacional de Atenção Oncológica (PRONON). In: $9^{\circ}$ CONGRESSO DA ASSOCIAÇÃO LATINO AMERICANA DE CIÊNCIA POLÍTICA. 26, 27 e 28 de julho de 2017. Anais... Montevideu, Uruguai.

CONTROLADORIA GERAL DA UNIÃO (CGU). Relatório de Avaliação dos Resultados da Gestão. n. 201701280. Brasília, 2016.

COBB, Roger W.; ELDER, Charles D. The Politics of Agenda-Building: An Alternative Perspective for Modern Democratic Theory. The Journal of Politics, v. 33, n. 4, p. 892-915, nov. 1971.

DEBONI, Fábio. Entrevista. Entrevistadora: Patricia Del Claro. Curitiba: 28 nov. 2018.

GRUPOS DE INSTITUTOS FUNDAÇÕES E EMPRESAS (GIFE). Investidores sociais se articulam em Rede Temática de Saúde. São Paulo: GIFE, 2015. Disponível em: <https://gife.org.br/investidores-sociais-se-articulam-em-rede-tematica-de-saude/>. Acesso em: 26 jan. 2019.

Balanço das Atividades da Rede Temática de Saúde 2014-2015. Apresentação. São Paulo, 2016a.

Rede Temática de Políticas Públicas discute a utilização dos incentivos fiscais pelos investidores sociais. São Paulo: 2016b. Disponível em <https://gife.org.br/rede-tematica-discute-a-utilizacao-dos-incentivos-fiscais-pelos-investidores-sociais/>. Acesso em 26 de janeiro de 2019.

Carta de Posicionamento GIFE Pronon Pronas, São Paulo, 2016c. Disponível em: <https://gife.org.br/atuacao-em-rede/saude/carta_posicionamento_gife_pronon_pronas-oficial/>. Acesso em: 26 jan. 2019.

Censo GIFE 2016. São Paulo: GIFE, 2017. 256p. Disponível em: 〈https://bit.ly/2LYsq9u〉. Acesso em: 20 nov. 2018.

INSTITUTO ONCOGUIA. Comissão do Congresso aprova proposta que prorroga o PRONON. São Paulo: Instituto Oncoguia, 15 set. 2015. Disponível em: <http://www.oncoguia.org.br/conteudo/pronon-comissao-do-congresso-aprova-proposta-que-prorroga-o-pronon/8122/990/>. Acesso em: nov. 2018. 
KINGDON, John. Agendas, Alternatives and Public Policies. Pearson, 2011.

MCCOMBS, Maxwell. A Teoria da Agenda: a mídia e a opinião pública. Tradução: Jacques A. Wainberg. Petrópolis: Vozes, 2009.

SOUZA, Celina. Políticas Públicas: uma revisão da literatura. Sociologias, Porto Alegre, ano 8, n. 16, p. 20-45, jul./dez.

Coordenação de políticas públicas. Brasília: Enap, 2018.

Estado da Arte da Pesquisa em Políticas Públicas. In: HOCHMAN, Gilberto; ARRETCHE, Marta; MARQUES, Eduardo (Orgs.). Políticas Públicas no Brasil. Rio de Janeiro: FIOCRUZ, 2007.

ZANDONADI, Lívia. Entrevista. Entrevistadora: Patricia Del Claro. São Paulo: 24 jan. 2019. 


\section{GIFE}

O Grupo de Institutos Fundações e Empresas (GIFE) é uma organização sem fins lucrativos que reúne associados de origem empresarial, familiar ou independente que investem em projetos de interesse público. Criado em 1989 como grupo de troca e colaboração e institucionalizado em 1995 por 25 organizações, tornou-se referência no campo da filantropia e do investimento social privado no Brasil.

Nesses mais de 20 anos de atuação, tem contribuído para o fortalecimento de práticas e ações a serviço do bem comum no país, trabalhando para expandir, qualificar e fortalecer o investimento social privado, diversificar e ampliar atores e recursos, criando referências e estimulando boas práticas de gestão, bem como articulando o setor com a sociedade e a agenda pública. Atualmente, o GIFE reúne mais de 150 associados que, somados, aportam mais de R\$ 3 bilhões por ano em projetos próprios e no apoio a projetos de terceiros.

\section{OS ARTIGOS GIFE}

A série Artigos GIFE publica reflexões e análises de pesquisadores brasileiros de diferentes áreas do saber com o objetivo de estimular, ampliar e disseminar a produção de conhecimento qualificado sobre o campo da filantropia, do investimento social privado e da sociedade civil no Brasil.

A partir da premissa de que a produção de conhecimento sobre esses temas tem um papel fundamental na expansão, diversificação e qualificação da ação pública pela sociedade, a iniciativa também pretende contribuir para ampliar as conexões entre o setor, as universidades e centros de pesquisa, promovendo e apoiando o envolvimento de novos atores com a temática e a circulação ampliada de ideias em torno dela.

Este artigo integra a primeira edição dos Artigos GIFE que foram selecionados na chamada pública lançada pelo GIFE em 2018, com base na avaliação de um comitê externo. Os textos se enquadram em um dos 16 temas propostos e dialogam com dados do Censo GIFE 2016 ou de pelo menos uma das seguintes pesquisas: BISC 2017, Pesquisa Doação Brasil e Perfil das Organizações da Sociedade Civil no Brasil, conforme estabelecido no edital da chamada.

É com alegria que publicamos os primeiros artigos dessa iniciativa que, a partir de então, se propõe a ser contínua, buscando apoiar e fomentar a produção de conhecimento sobre esse campo no Brasil. 
OGIFE 


\section{A AUTORA}

\section{Patricia Del Claro}

Mestre em Ciência Política e graduada em Comunicação Social - Relações Públicas, ambos pela Universidade Federal do Paraná (UFPR) em 2013 e 1998, respectivamente. Tem experiência de mais de 15 anos na gestão de projetos para fundações, institutos empresariais e empresas, organizações da sociedade civil (OSCs) e órgãos públicos. Atualmente é coordenadora de projetos no Hospital Pequeno Príncipe. Foi consultora do Programa das Nações Unidas para o Desenvolvimento (PNUD) para o acompanhamento das ações do Programa Cultura Viva do Ministério da Cultura (MinC) na região Sul do Brasil. Foi membro da coordenação do Fórum de Educação em Direitos Humanos do Paraná (2007/2008) e integrante do Núcleo Interdisciplinar de Estudos do Terceiro Setor da UFPR. 


\title{
artigos GIFE
}

\author{
Supervisão: José Marcelo Zacchi e Erika Sanchez Saez \\ Coordenação: Graziela Santiago \\ Suporte: Carolina Magosso \\ Comitê de seleção: Ana Lúcia D'Império Lima, \\ Aron Belinky, Beatriz Azeredo e Paula Galeano \\ Projeto gráfico e diagramação: Dafne Rozencwaig Souza \\ Revisão: Amanda Proetti \\ Impressão: Forma Certa
}

(C) 2019 GIFE - Grupo de Institutos Fundações e Empresas

DOI: doi.org/10.4322/978-85-88462-37-3-06

\section{(c) (P) 6}

Este material é disponibilizado sob a licenca Creative Commons Atribuição Não Comercial 4.0 Internacional. http://creativecommons.org/licenses/by-nc/4.0

As opiniões e análises expressas nesta publicação não necessariamente refletem as do GIFE.

\author{
Apoio Institucional \\ Fundação Lemann \\ Instituto C\&A \\ Instituto Unibanco
}

QBFEF 